$\underline{\text { Article }}$

\title{
Global Pandemics and the Economics of Value Chains: COVID-19 and the Production of Medical Devices
}

\author{
Lilac Nachum ${ }^{1}{ }^{\text {a }}$ \\ ${ }^{1}$ Baruch College, City University of New York, USA \\ Keywords: medical devices, government policy, covid-19, pandemics, value chains \\ https://doi.org/10.46697/001c.24402
}

\section{AIB Insights}

Vol. 21, Issue 2, 2021

\begin{abstract}
Pandemics change the dynamics of value chains in fundamental ways, and particularly of those producing the medical devices needed to fight them. This paper shows that the rationale for organization of the production of these devices differs from that of most other products. Varying trade-offs between the benefits of global integration and the imperatives of secured and speedy supply favor different production modes. Value chains of different geographic scales - local, regional and global - are suitable for different medical devices. A model developed based on these variations could assist policymakers in designing differentiated policies towards different medical devices. As well, the model provides insights that could aid supply chain managers and academics rethinking the determinants of supply chain structures across industries.
\end{abstract}

Pandemics abruptly change value chain dynamics, as the COVID-19 outbreak and its aftermath have shown. While this effect is notable across industries, it is particularly apparent in relation to the medical devices ${ }^{1}$ needed to treat pandemics' causes and arrest their spread. This article examines the challenges that pandemics pose to the production and supply of medical devices and their implications for the organization of their production. The experience of COVID-19 is employed to illustrate how abilities to scale production rapidly and secure speedy supply have come to replace cost, skills and resource availability considerations that prevail elsewhere. An understanding of these dynamics is important to government policymakers, supply chain managers and academics who study supply chains.

These constituencies need to recognize the distinction among types of medical devices that represent varying trade-offs between the benefits of globally-dispersed production and the imperatives of secured supply and speed of delivery. This distinction requires differentiated responses towards different types of medical devices. It offers rationale for protectionist policies designed to ensure self-sufficiency of certain devices, including when they require economically sub-optimal arrangements, and the initiation of global and regional collaborations to secure reliable supply of others. An important role is assigned also for interna- tional organizations such as the World Health Organization (WHO) and the World Trade Organization (WTO) to centrally administer mismatches between supply and demand for medical devices on a global scale during pandemics.

\section{PANDEMICS AND THE FUNDAMENTALS OF MEDICAL DEVICE VALUE CHAINS}

Globally-integrated production is driven by two economic forces, related to the actual production of products and services and to their supply to markets. Country differences in costs, skills and resource availability offer economic rationale for spreading production globally to take advantage of these differences. Low trade costs make it economically feasible to link separate parts of production via trade and secure efficient and low-cost supply to markets that may reside far away from the location of the production (Baldwin, 2016). Prior to the onset of COVID-19, the production and supply of medical devices were largely based on these principles (Gereffi, 2020), as analyses of trade data of these products show. ${ }^{2}$ Pandemic outbreaks challenge the logics of both global integration of the production and that of the supply.

On the production side, production capacity becomes a

\footnotetext{
a Contact author: Lilac.Nachum@baruch.cuny.edu

1 Definitions of the medical devices sector vary considerably across countries. In this article, I follow the definition of the WHO https://www.who.int/medical_devices/full_deffinition/en/which is adopted by many other international organizations. Accordingly, this sector includes diagnostic and therapeutic equipment used for treatment of disease, development of drugs, and clinical trials. These range from low-tech PPE equipment to sophisticated diagnostic equipment, patented drugs and immunological products. For a related examination of decentralizing clinical trials during the pandemic, see Dunlap et al. (2020).
}

2 http://www.cepii.fr/CEPII/en/bdd_modele/presentation.asp?id=37, HS12_BACI 
major determinant of the organization of production. Pandemics are rare events - a hundred years elapsed since the last global pandemic, the Spanish Flu - and are often unpredictable. When they occur, they push demand to levels that have no relation to those of ordinary times, and pose major challenges to production capacity. These conditions assign outmost significance for flexibility and ability to rapidly scale up production (Perez-Batres \& Treviño, 2020). Cyclical fluctuations of demand, caused for example by weather conditions, natural disasters, etc., are apparent in many industries, but the extent of cyclicality and its abrupt nature in medical devices needed to deal with pandemics tend to be more substantial than in other industries. Indeed, credit rating agencies treat medical devices as one of the most vulnerable sectors to disruptions (albeit with considerable variability within the sector). These dynamics also change the economics of inventory and the balance between the cost and benefit of holding inventory.

Moreover, cost of production, a major driver of globallyintegrated production, is of lesser importance in relation to medical devices, notably during times of pandemics. Price elasticity is very high when human lives are at stake and the availability of substitutions is limited, diminishing pressure to cut costs and reduce prices. Yet another distinctive feature of medical devices is risk of intellectual property right (IPR) violations and concerns regarding fraudulent products. Risk of IPR violations dictates the organization of production across industries, but it is more critical in relation to medical devices. Fake N95 masks exported from China and other locations after the outbreak of COVID-19 threatened millions of frontline workers lives.

In addition, the life cycle of the virus from its initial appearance through penetration, replication and full release unfolds at different times and rates around the world, which leads to variations in demand for medical devices across countries. Variations in prevalence rates of the virus also affect local demand. Country differences in immunity have been documented extensively, and were apparent in earlier epidemics, for instance Ebola and AIDS. ${ }^{3}$ These variations create mis-matches between production capacity and demand.

For instance, due to the country's early COVID-19 outbreak, China experienced surging local demand that exceeded local production capacity. Chinese Daigou bought medical supplies in Australia and sold them in China. ${ }^{4}$ The US exported masks and ventilators to China during this period (Zhang, Mansfield, \& Pulver, 2020). ${ }^{5}$ By the time COVID-19 hit the US and Europe, China had started to show signs of recovery that reduced local demand and freed production capacity for exports. Life-cycle considerations affect production of other products as well, for instance hightech products in which technology life-cycles dictate production dynamics, but these influences are much accelerated in relation to medical devices where cyclicality of demand relates to saving people's lives.

Pandemics affect the rationale for the organization of production also via their impact on supply and distribution. Speedy and secured supply assume levels of importance that by far exceed that of other products. Speed to market has become an important competitive imperative across industries. The emergence of the so-called 'fast fashion' is a case in point. However, speed of supply of medical devices is not about filling up stores' shelves with ever-changing fashion merchandise but rather a matter of saving lives of patients dying due to shortage of equipment.

In parallel, however, global pandemics slow down the movement of intermediaries and final products across countries. Following the outbreak of COVID-19, fragmented sources of supplies connected to each other via trade were abruptly interrupted by logistic difficulties as factories confronted irregularities of labor and supply, port closures, and customs slowdowns (Perez-Batres \& Treviño, 2020). Moreover, pandemics trigger protectionist measures and trade restrictions that further slow down the pace of moving products and services across countries. An UNCTAD analysis of policy measures introduced around the world during the second half of 2020 shows the highest increase of protectionist measures in two decades (UNCTAD, 2021). The adoption of different policy responses and safety standards towards medical devices caused additional delays. Restrictions on cross-border transactions on grounds such as environmental regulations and safety standards prevail across industries, but they tend to be particularly apparent in relation to medical devices, notably during pandemics (although in some cases, severe shortage of supply served as a countervailing force for regulatory scrutiny). Table 1 presents a summary of determinants of the organization of production of medical devices compared to other lowskilled, labor-intensive industries and human- and physical-capital-intensive ones. These categories refer to large and heterogenous groups of industries and sub-sectors whose dynamics may vary in relation to specific dimensions in Table 1. For instance, capital-intensive products include products whose value relative to transportation cost varies, ranging from mobile phones where transportation costs are negligible to cars where they are substantial. Further, designation of level of importance might involve subjective judgement. Notwithstanding these reservations, the table highlights the distinction of medical devices in relation to other product categories and the need for special attention to the organization of the production of this sector.

\footnotetext{
3 See the WHO’s Global Burden of Disease Project: http://www.healthdata.org/gbd.

4 Daigou purchase commodities outside China for sales in China. I thank an anonymous referee for sharing this story.

5 In addition to market-driven dynamics to level out demand/supply differences, US exports were driven also by political considerations. This draws attention to the consequences of government involvement in the fight against pandemics, where political considerations interfere with economic ones. I thank an anonymous referee for raising this point.
} 
Table 1. Determinants of Organization of Production: Medical Devices versus Other Industries

\begin{tabular}{|c|c|c|c|}
\hline \multirow[b]{3}{*}{ Determinants of: } & \multicolumn{3}{|c|}{ Level of Importance } \\
\hline & \multirow[b]{2}{*}{ Medical Devices } & \multicolumn{2}{|c|}{ Other Industries } \\
\hline & & Labor-intensive industries & Capital-intensive industries \\
\hline \multicolumn{4}{|l|}{ Global Integration of the Production } \\
\hline Cost differential & low & high & moderate \\
\hline Skills differential & high/moderate & high & high \\
\hline Resource differential & moderate & high & moderate \\
\hline Regulatory restrictions & high & low & moderate \\
\hline IPR violations & critical & moderate & high/critical \\
\hline Product life cycle & critical & low & moderate/high \\
\hline Flexibility of scaling production & critical & moderate & moderate \\
\hline \multicolumn{4}{|l|}{ Delivery and Supply } \\
\hline Transportation costs & low/moderate & high & low/moderate/high \\
\hline Transportation speed/distance & critical & moderate & moderate \\
\hline Trade barriers & high & low & moderate \\
\hline
\end{tabular}

\section{MEDICAL DEVICES ARE NOT ALL ALIKE}

The idiosyncrasies of medical devices outlined in Table 1 manifest in different ways and to varying degrees in relation to different devices. As noted (footnote 1), the medical device sector is highly heterogenous in terms of factor intensity, intellectual property content, ${ }^{6}$ trade cost and regulatory demands. ${ }^{7}$ These differences affect both the advantages of global integration of the production and the importance of efficient supply and timely delivery, and favor production arrangements on different geographic scales - whether local, regional or global (Figure 1).

Quadrant-1 medical devices, such as advanced diagnostic equipment, are characterized by low advantages of global integration, a result of factors such as low-price elasticity, specialized production and high skills. Cost saving via global integration is likely to be small, because the high skills intensity confines the production to high-cost countries. These factors combine with high importance of efficient supply, for instance, due to high transportation costs. Such combination favors local value chains, supplemented by inventory to safeguard against unexpected supply shortages due to short-term constraints on production capacity.

In quadrant- 2 devices, skills, costs and resources vary a great deal across countries, and price is an important competitive factor, making integrated production highly advantageous. Examples of such medical devices include various appliances employed in laboratory and medical surgeries. The need for efficient and speedy supply, however, requires

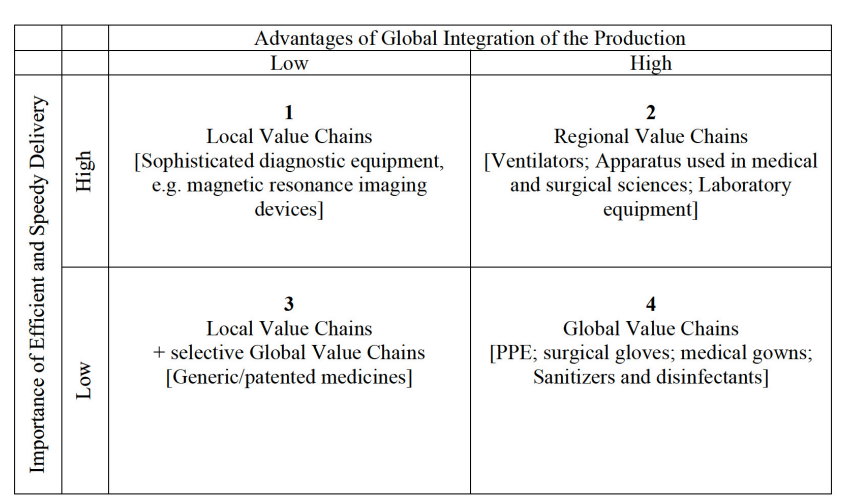

\section{Figure 1. Production Arrangement of Medical Devices (Developed country perspective)}

geographic proximity among producing countries and between them and markets. This combination is best supplied via regional value chains, ideally among countries connected by regional trade agreements that reduce bordercrossing obstacles.

Low advantages of global integration, a result of issues such as risk of IPR violation, combined with lesser importance of speedy delivery, a result of issues such as lowcost inventory, characterize quadrant-3 devices. Such circumstances favor local value chains, perhaps with selective global value chains to secure supply in case of unexpected short-term shortages. Drugs - both generic and patented -

6 These differences are notable in patent variations within the sector: http://www.samed.org.za/DynamicData/LibraryDownloads/56.pdf

7 Most countries distinguish among different medical devices for the purpose of regulatory scrutiny. See the US classification https://www.fda.gov/about-fda/cdrh-transparency/overview-medical-device-classification-and-reclassification and ISO classification for regulatory intervention https://www.iso.org/iso-13485-medical-devices.html 
offer an example of such products.

Medical devices in quadrant-4, such as PPE, sanitizers, gloves and the likes, are suitable for globally-integrated production, in which value chains are based on country differences in costs, skills and resources, and low-cost trade enables efficient supply to markets. These devices are often low-skill, labor-intensive products, making the cost saving of global production substantial. ${ }^{8}$ Low product-specificity and multiple sources of supply for these devices enable secure, efficient and speedy supply. Low switching costs among multiple sources of supply could be employed to evoke threat of exit as an at least partial guard against fraudulence. The simplicity of the devices eases the identification of such occurrences.

The unpredictable nature of pandemics entails that outbreaks might cause temporary shortages of supply domestically and globally. These might challenge the underlying logic of Figure 1 and necessitate some short-term deviations from this logic. Rare and exceptional events like global pandemics are guided by different dynamics than those that prevail in ordinary times and might require exceptional responses (Perez-Batres \& Treviño, 2020).

Two responses, on their own or combined, can be employed under such circumstances. One is inventory, probably managed by governments as the constituency that has the resources to handle inventory that may lay idle for years and decades. This approach is pursued by many governments in relation to defense equipment, and appears adequate for medical devices as well. The other alternative is temporary shifts of resources and production capacity from other industries to medical devices. The US imploration of the Defense Production Act to demand car companies to produce ventilators during the COVID-19 outbreak, or the Australian government's boost for 3D-printing companies to produce face shields, and to alcohol producers to switch production to hand sanitizers are cases in point. ${ }^{9}$ Such changes may also occur without government intervention, when companies voluntarily shift production capacity to products needed to fight pandemics. New Balance's transformation of its production from shoes to PPE suggests an example. Although in violation of the logic that underlies Figure 1, these arrangements might be necessary to meet short-term shortages.

\section{ROLE FOR POLICYMAKERS}

The rationale for policy intervention in the production and supply of medical devices needed to fight pandemics is stronger than in most other sectors. The logic for the organization of production of medical devices does not always coincide with economic considerations and may impose some trade-offs between the two. Such situations disincen- tivize private investment and require government involvement. Moreover, the production of many medical devices involves high-risk investments whose returns are uncertain. The economics of inventory and the need to have a standby manufacturing capacity to meet unpredictable demand also call for government involvement. Furthermore, the scale needed to fight global pandemics exceeds the capacity of private actors, including the largest and most powerful of them, and requires policy intervention.

Two constituencies have a role to play in securing the effectiveness of production and supply of medical devices: national governments and international organizations. Governments around the world have been playing major roles in the provision of medical devices during the COVID-19 pandemic. The global nature of pandemics requires a centralized approach to the fight against them and calls for the involvement of international organizations as well. By virtue of their different mandates and sources of power, these constituencies have different mechanisms to affect the production and supply of medical devices (Table 2).

Policy responses to COVID-19 at the national level in most countries reflected strong inclinations towards selfsufficiency and increased local production capacity across all medical devices (Bazel-Shoham \& Shoham, 2020). Many governments also banned exports of these devices (ITC, 2020; The Economist, 2020). The effectiveness of these efforts in securing the supply of medical devices under the best economic terms, however, is not apparent. Rather, there is a need for differentiated policy response, in line with the principles summarized in Figure 1. Such responses range between the introduction of protectionist measures to develop local production capacity and increased integration in order to secure external supply. The choice between the two reflects the tradeoffs between the advantages of global integration and the importance of speed and efficiency of supply.

Thus, beyond the need to offer urgent remedies for short-term shortages, protectionist policies are adequate only for quadrant- 1 and some quadrant- 3 devices where the need to secure speedy and reliable supply exceeds the benefits of global integration (Figure 1). Governments may support local producers of these devices and, as appropriate, protect them from import competition. They may also form public-private partnerships for the production and supply of these medical devices. These partnerships have particular appeal in that they lessen governments' inefficiencies and enable private players to leverage their advantages in a manner that would not be feasible on their own (Kivleniece \& Quelin, 2012).

The economic case for self-sufficiency in other devices, as those in quadrants 2,4 , and some quadrant- 3 , is weak

8 The classification of medical devices as low-skill, low-tech products is at times misleading. For instance, sophisticated, high-tech filters are used in the production of certain types of facemasks, which are often referred to as low-tech devices. Distortions might originate also due to the level of aggregation. For instance, standard facemasks that the general public wears and sophisticated ones used by healthcare workers are in the same category.

9 I thank an anonymous referee for this insightful point. 
Table 2. Production Arrangements of Medical Devices: Role for Policy

\begin{tabular}{|l|l|l|}
\hline \multirow{2}{*}{ Constituencies: } & \multicolumn{1}{|c|}{ Policy tools } & \multicolumn{1}{c|}{ Illustration } \\
\hline \multirow{2}{*}{ National governments } & $\begin{array}{l}\text { Differentiated policy approach: } \\
\text { protectionism versus openness }\end{array}$ & $\begin{array}{l}\text { From self-sufficiency and development } \\
\text { of local capacity to deep global } \\
\text { integration to ensure global supply }\end{array}$ \\
\cline { 2 - 3 } & $\begin{array}{l}\text { Differentiated policy approach: } \\
\text { geographic scale of supply chains }\end{array}$ & $\begin{array}{l}\text { Incentives to firms for desired } \\
\text { geographical scale of supply chains }\end{array}$ \\
\hline \multirow{2}{*}{ International Organizations } & $\begin{array}{l}\text { Central administration of production; } \\
\text { removal of supply/demand mismatches } \\
\text { on a global level }\end{array}$ & $\begin{array}{l}\text { WHO: centralized forum to identify } \\
\text { mismatches and orchestrate } \\
\text { agreements to level them out }\end{array}$ \\
\cline { 2 - 3 } & $\begin{array}{l}\text { Removal of trade barriers in medical } \\
\text { devices }\end{array}$ & $\begin{array}{l}\text { WTO: special status for medical devices } \\
\text { in trade policy and global trade } \\
\text { agreements }\end{array}$ \\
\hline
\end{tabular}

or nonexistent (McKinsey \& Company, 2020). The Pharmaceutical Researcher and Manufacturers of America has argued that reconfiguration of globally-dispersed pharmaceuticals induced by government pressure and incentives to localize value chains, may disrupt, rather than secure, medical supplies (Longo, 2020). In relation to such devices, governments should employ unilateral and multilateral trade agreements to secure supply via global (quadrant-4) and regional (quadrant-2) value chains. The critical importance of speedy and reliable supply assigns heightened importance to trade agreements that affect the costs and speed of crossing borders. Government trade policies shape firms' preferences towards local, regional or global value-chains, and these policies should be employed to incentivize firms to make choices that are aligned with the rationale of Figure 1.

In addition to national governments, there is also an important role for international organizations. Cyclical demand for medical devices that sprung up at different times in different countries, and the strong imperative of speed to market, assign critical roles for international organizations in pulling capabilities from around the world to respond to global pandemics. The WHO is the apparent contender for centrally administrating production and supply that would level out mismatches between supply and demand on a global scale. The WHO, perhaps in collaboration with the WTO, should also oversee the introduction of liberal trade policies to eliminate these mismatches, and assign medical devices special status in trade agreements that is aligned with their distinctive attributes (Table 1).

The nuanced approach advanced in this paper towards the organization of production offers tools for thinking about this issue in other sectors and industries, notably those characterized by cyclical and unpredicted demand that must be fulfilled instantly, for instance, the defense sector. It also calls for re-thinking of the comparative advantages that affect the organization of production and structure of value chains to include countries' geographic locations in relation to markets and flexibility of production capacity, as they relate to industrial structure and the nature of labor markets across countries.

\section{ACKNOWLEDGEMENT}

I thank William Newburry, Associate Editor of the AIB Insights, for excellent editorial guide throughout the revision process. I acknowledge with gratitude constructive and insightful comments of three anonymous referees on earlier drafts of the paper. This paper originated in a study prepared for UNIDO Industrial Analytics Platform. UNIDO support of the study is gratefully acknowledged.

\section{ABOUT THE AUTHOR}

Lilac Nachum's current research interests include global supply chains and value creation in a global world, and the relationship between firms, society and governments as they shape firms' international strategies. Her research was published in the Academy of Management Journal, Strategic Management Journal, and the Journal of International Business Studies, among others. She serve on the editorial boards of these and other leading journals in international business. She am a Fellow of the AIB and a 2021-22 Fulbright Scholar for Africa.

Submitted: January 06, 2021 EDT, Accepted: May 22, 2021 EDT 


\section{REFERENCES}

Baldwin, R. E. 2016. The Great Convergence: Information Technology and the NewGlobalization. Cambridge, Mass: Harvard University Press.

Bazel-Shoham, O., \& Shoham, A. 2020. Rethinking Overseas Production: The Case of COVID-19 and Negative Externality. AIB Insights, 20(3). https://doi.org/10.46697/001c.17690.

Dunlap, D., Santos, R. S., McManus, D. D., Buchholz, B. O., Hafer, N. S., et al. 2020. New opportunities and cautionary insights about decentralizing and deglobalizing clinical trials during the Great Lockdown. AIB Insights, 20(3). https://doi.org/ 10.46697/001c.17692.

Gereffi, G. 2020. What does the COVID-19 pandemic teach us about global value chains? The case of medical supplies. Journal of International Business Policy, 3(3): 287-301.

ITC. 2020. COVID-19 Temporary Trade Measures. ht tps://www.macmap.org/covid19.

Kivleniece, I., \& Quelin, B. V. 2012. Creating and capturing value in public-private ties: Aprivate actor's perspective. Academy of Management Review, 37(3): 272-299.
Longo, N. 2020, May 14. Setting up a pharmaceutical manufacturing supply chain is a complex andlengthy process. The Catalyst, PhRMA.

McKinsey \& Company. 2020. Risk, resilience, and rebalancing in global value chains. McKinsey Global Institute report.

Perez-Batres, L. A., \& Treviño, L. J. 2020. Global supply chains in response to COVID-19: Adopting a real options mindset. AIB Insights, 20(3). https://doi.org/10.46697/001c.17884.

The Economist. 2020, March 26. If you thought the trade war was bad for global commerce...

UNCTAD. 2021, February. Investment Policy Monitor, (24).

Zhang, D., Mansfield, E., \& Pulver, D. V. 2020, April 3. U.S. exported millions in masks and ventilators ahead of the coronavirus crisis. USA TODAY. 